\title{
Examination of vertical displacements at non-permanently fixed points
}

\author{
Robert Gradka ${ }^{1, *}$ \\ ${ }^{1}$ Wrocław University of Science and Technology, Faculty of Geoengineering, Mining and Geology, 27 Wyb. Wyspiańskiego St., \\ 50-370 Wrocław, Poland
}

\begin{abstract}
The aim of this paper was to analyze vertical displacements in four different test areas, with various types of surfaces, without permanently stabilized measuring: points and control network, using the same measurement method. The first stage involved measuring selected test areas with a number of measuring points that reliably reflect the surface and to construct the DEM. The second stage involves acquiring of a grid of control points, evenly distributed in the test area, used to assess the accuracy of the DEM. The last stage involved the analysis of the acquired results, including the application of an original program to calculate vertical displacements. In order to conduct the analysis the "blind test" was introduced, which allowed to perform formal analyses, i.e. verification of the accuracy of models constructed based on direct measurements. In this program (based on the IDW interpolation method), the study of the dependence of introducing fixed points (given measurement error), to measured survey points was carried out. It was possible to determine vertical displacements between measurements in each area, calculate the accuracy of the mapping of the terrain surface, fit the DEM into the actual terrain, as well as obtain the parameters of the approximate planes.
\end{abstract}

\section{Introduction}

Deformations of terrain occur mainly due to the changes of load on the ground, in the level of groundwater, as well as any land sliding. Also, the progressing investments (deep excavations or other earthworks) may pose a threat to neighboring buildings and may be the reason for monitoring the displacements of land surface and structural monitoring of buildings [1,2]. Especially in the areas of mining activities and other hazardous areas, measurements of deformations and displacements in terrain include important land surveyors' work [3, 4]. In such areas, measurements of displacements and deformations provide information on the hazard level to building security and can prevent the occurrence of a construction disaster. In addition, the displacement measurement results are also used to verify assumed displacement values $[1,5]$. The choice of measuring method and the terrain deformation study method are determined by a number of factors, including [6]:

- the desired accuracy of evaluation of point displacements, dependent on the types of analyzed structures,

- the density and size of the control grid,

- the type of displacements determined (relative, absolute, vertical, horizontal, 3D),

- the rate of changes occurring.

Determining terrain deformation, such as vertical and horizontal displacements, requires highly accurate land surveying measurements. In classical land surveying, determination of vertical displacements commonly employs the method of precise leveling, while in the case of horizontal displacements, angular and linear measurements in control grids [7-10]. The author has decided, however, that the determination of displacements in the terrain will involve geometric leveling, ant not precise leveling, since the measurement will be performed on random points, placed on the ground, not permanently fixed thereon.

In the literature, you can find many items on surveying vertical displacements, however, mainly on fixed points in the terrain or directly on surveyed structures. The author attempted to examine vertical displacements, both on measurement points and on the geodetic control network which have not been permanently stabilized in the terrain, between the first and the second measurement.

\section{Characteristics of test areas and measurement methods}

Four areas located in the city of Krakow were measured twice (the first measurements took place in 2016, the second in 2017). Two of them were areas with low vegetation (grass), while the third is the old airport (concrete), and the last one - the area of one of the city parks (mixed: asphalt and grass). The shape, layout and location of the measurement dot grid is presented in the Fig. 1 (example of area no. 1), in the plane geodetic

\footnotetext{
Corresponding author: robert.gradka@,pwr.edu.pl
} 
coordinate system - "PL-2000". Each of the research area was approximately $95 \mathrm{~m}$ long and $65 \mathrm{~m}$ wide.

The study areas were selected in such a manner so that the points of the geodetic network were as close as possible to each other. The points of the measuring network were stabilized only temporarily in the terrain and located in a different place, for each of the measurements. Each of the survey point was marked out according to the assumed measurement grid (11x11 points), consisting of a total of 121 points (Fig. 1), in each of the areas (total: 968 of survey points for both measurements). The points were distributed evenly in relation to one another, according to the GRID [11, 12], measured (using a TOPCON GPT-3000 total station) and marked for the duration of the measurements with a peg, pin or a nail (depending on the test area). Each of the point (survey and network) was also measured using the GNSS satellite measurement technique - the Trimble R8 receiver, and finally measured using the Leica Sprinter $150 \mathrm{M}$ code leveler to obtain the heights needed for analysis. The measured points also served to build and evaluate the GRID DEM accuracy [11-13].
To perform the repeated measurements, all points were marked on each object using GNSS technique (without stabilization), and then aluminum leveling staff was placed near the original point and re-measured with a code leveler. Due to the fact that the author did not want to faithfully reproduce the points from the first measurement, but only to be in the approximate position in relation to the points from the initial measurement, hence it was reasonable to use the GNSS receiver to determine the points. The accuracy of the determination of points from the first measurement is not accidental. The leveling staff has the spacing of ca. $60 \mathrm{~mm}$ at the base, therefore, after determination of points with GNSS with the accuracy of $\pm 30 \mathrm{~mm}$, the probability of measuring a point at the very same (initial) spot or in its very near proximity is high. The re-measurement was to show differences in the height of the points, from the initial and subsequent measurements, the same terrain relief (the same range of the grid) and to investigate the displacements of the objects (if any occur) using nonfixed points and only reproduced by the GNSS technique.

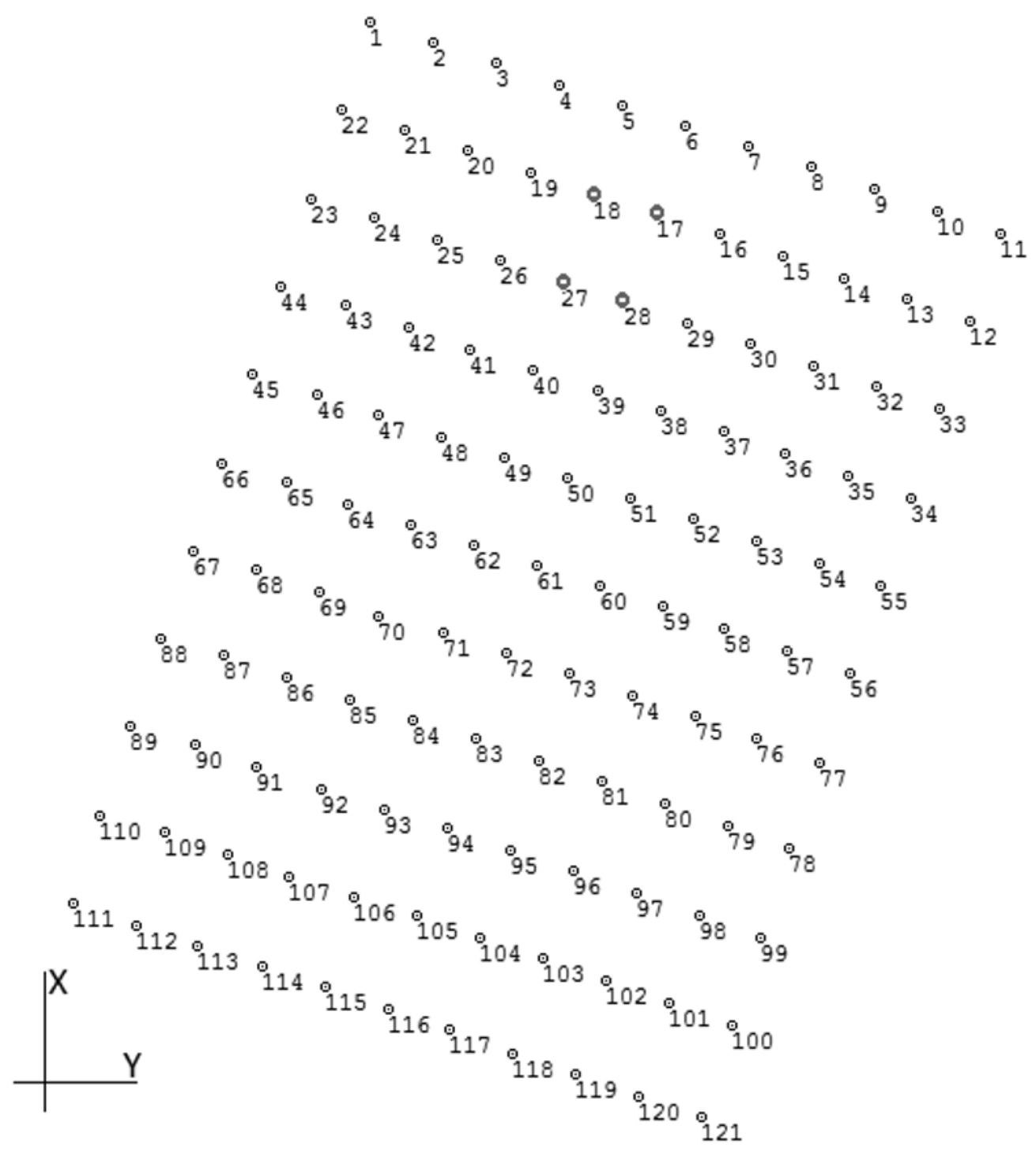

Fig. 1. The shape, layout and location of the points of the measurement grid (example area 1). 


\section{The analysis of vertical displacements and plane parameters}

Knowing that in a small area mass displacements can be approximated with any plane $[7,14]$ the question arises: is it possible to obtain pre-set values of plane parameters, with different combinations of non-fixed points (in initial and secondary measurement) and theoretically fixed points (adopted for the time of calculation as a permanent but not fixed in the field in reality)? The "blind test", carried out by the author, was an experiment used to determine vertical displacement between measurements in a given research areas, depending on the number of fixed points entered (with a given measurement error) to the survey points.

It was decided to analyze the data obtained from direct measurements in the original program, based on the data interpolation method - IDW (Inverse Distance Weighting) [14-16]. The IDW method was chosen for the analysis due to the easiness to program the algorithm. For each measured areas, several additional conditions and parameters were introduced:

- all coordinates are in a local system - untransformed to the "PL-2000" - coordinate system,

- GRIDs were generated in the shape and size of the rectangles consisting of the next four measurement points, nearest to each other (Fig. 1 - red dots / points no.: 17, 18, 27, 29) - coincide with a grid of measurement points in a local system,

- the number of fixed points is: 0-5 - randomly selected among measured points,

- measurement error for a fixed point is $\pm 2 \mathrm{~mm}-$ determined by the author,

- average error for measuring the height of the point is $\pm 30 \mathrm{~mm}$,

- nearest point searching radius is $10 \mathrm{~m}$,

- value of function for coordinates is a plane with 0 parameters of the general equation of the plane,

- number of repetitions for calculations per each area and each fixed point is 50 ,

- $\quad$ ex, ey, H0 - vectors of changes in the position of the calculated plane from the second measurement, relative to the plane obtained from the first measurement - plane “ 0 ").

The program works by choosing a predetermined number of random points from a given area, with a preestablished height error based on a given number measurement and repetitions of calculations. The program was created in the $\mathrm{C}++$ environment.

For each area, data needed to be prepared for the calculations in the form of text files (Tables 1-3). For the first measurement, the file (Table 1) contains as follows: coordinates (local) X, Y, height above sea level $\mathrm{H}$ and average error for measuring the height of the point $\mathrm{mH}$ $[\mathrm{mm}]$.
Table 1. File fragment with data for the calculations (first measurement).

\begin{tabular}{|c|c|c|c|}
\hline $\mathbf{X}$ & $\mathbf{Y}$ & $\mathbf{H}$ & $\mathbf{m H}$ \\
\hline 30.570 & 245.714 & 202.789 & 30 \\
\hline 33.668 & 240.376 & 202.797 & 30 \\
\hline 36.774 & 234.971 & 202.837 & 30 \\
\hline 39.840 & 229.613 & 202.875 & 30 \\
\hline 50.919 & 228.852 & 202.592 & 30 \\
\hline 47.834 & 234.240 & 202.585 & 30 \\
\hline 44.727 & 239.603 & 202.604 & 30 \\
\hline
\end{tabular}

The text file for the secondary measurement (Table 2) - in consecutive lines, the coordinates (local) X, Y, height $\mathrm{H}$, the average error for measuring the height of the point $\mathrm{mH}[\mathrm{mm}]$ and the value of the function for the coordinate data Hfunk - the plane with the 0 parameters.

Table 2. File fragment with data for the calculations (secondary measurement).

\begin{tabular}{|c|c|c|c|c|}
\hline $\mathbf{X}$ & $\mathbf{Y}$ & $\mathbf{H}$ & $\mathbf{m H}$ & Hfunk \\
\hline 30.570 & 245.714 & 202.809 & 30 & 0 \\
\hline 33.668 & 240.376 & 202.814 & 30 & 0 \\
\hline 36.774 & 234.971 & 202.850 & 30 & 0 \\
\hline 39.840 & 229.613 & 202.884 & 30 & 0 \\
\hline 50.919 & 228.852 & 202.596 & 30 & 0 \\
\hline 47.834 & 234.240 & 202.584 & 30 & 0 \\
\hline 44.727 & 239.603 & 202.611 & 30 & 0 \\
\hline
\end{tabular}

GRID network file (Table 3) - in consecutive lines, the coordinates (local), $\mathrm{X}, \mathrm{Y}$, the function value for Hfunk coordinates data.

Table 3. GRID file fragment with data for the calculations.

\begin{tabular}{|c|c|c|}
\hline $\mathbf{X}$ & $\mathbf{Y}$ & Hfunk \\
\hline 111 & 223 & 0 \\
\hline 114 & 223 & 0 \\
\hline 117 & 223 & 0 \\
\hline 120 & 223 & 0 \\
\hline 123 & 223 & 0 \\
\hline 12 & 226 & 0 \\
\hline 15 & 226 & 0 \\
\hline 18 & 226 & 0 \\
\hline
\end{tabular}

Control file (Table 4) of the calculating program contains (in lines):

1. Interpolation distance for a given point [m] (the maximum range in which the points are taken to interpolation), 
2. safety parameter [m] (if the measuring point lies exactly where computation point, it would be an error, because there would be a division by zero),

3. measurement error for a fixed (adopted as a permanent) point $[\mathrm{mm}]$ - determined by the author,

4. number of generated fixed (adopted as a permanent) points,

5. number of repetitions for calculations,

6. file localization and name series 1 ,

7. file localization and name series 2 ,

8. grid file localization and name,

9. results file localization and name.

Table 4. Control file fragment with data for the calculations.

\begin{tabular}{|c|c|}
\hline Line & Attribute \\
\hline 1 & 10.0 \\
\hline 2 & 0.1 \\
\hline 3 & 2.0 \\
\hline 4 & 0 \\
\hline 5 & 50 \\
\hline 6 & D: $\backslash$ s1.txt \\
\hline 7 & D: $\backslash$ s2.txt \\
\hline 8 & D: $\backslash$ grid.txt \\
\hline 9 & D: $\backslash$ result.txt \\
\hline
\end{tabular}

The result of the calculations is the result file (Table 5), which contains, in the line for each given calculation result, consecutively:
- number of the calculation,

- mean difference of height between series 1 and series 2,

- root mean square error (RMSE) - the root of the sum of error squares model estimation,

- $\quad \boldsymbol{e x}$ (vector component along the $\mathrm{X}$ axis) parameter of the plane function - difference between the value of the "0" function and a plane approximated by calculating the proprietary program,

- $\quad$ ey (vector component along the $\mathrm{Y}$ axis) parameter of the plane function - difference between the value of the " 0 " function and a plane approximated by calculating the proprietary program,

- $\quad H 0$ (vector component along the $\mathrm{Z}$ axis) parameter of the plane function - difference between the value of the " 0 " function and the values of functions interpolated by the program; the actual displacement relative to the " 0 " plane and the 0 height.

\section{Received results}

For each area, the results of the calculations for a given number of fixed (adopted as a permanent) points with 50 repetitions of calculations are presented in tables (6-9). The tables contain data from the result files, i.e: the average difference between series [m], root mean square error (RMSE) [m], three plane parameters (ex, ey, H0), as well as the number of fixed points [items] and calculated minimum and maximum differences between series $[\mathrm{m}]$.

Table 5. Fragment of the calculation result file.

\begin{tabular}{|c|c|c|c|c|c|}
\hline No. & Difference & RMSE & ex & ey & Ho \\
\hline 1 & 0.0030 & 0.0103 & 0.003040 & -0.001237 & 0.00121 \\
\hline 2 & 0.0031 & 0.0107 & 0.003023 & -0.001281 & 0.00475 \\
\hline 3 & 0.0026 & 0.0100 & 0.003049 & -0.001289 & 0.00474 \\
\hline 50 & 0.0020 & 0.0101 & 0.003060 & -0.001283 & 0.00337 \\
\hline
\end{tabular}

Table 6. Compilation of calculations from the result file for area 1 in the local system.

\begin{tabular}{|r|c|c|c|c|c|c|}
\hline Number of fixed points & $\mathbf{0}$ & $\mathbf{1}$ & $\mathbf{2}$ & $\mathbf{3}$ & $\mathbf{4}$ & $\mathbf{5}$ \\
\hline Min. difference between series [m] & -0.005 & -0.0054 & -0.0051 & -0.0051 & -0.0052 & -0.0052 \\
\hline Max. difference between series [m] & -0.005 & -0.0046 & -0.0034 & -0.003 & -0.0031 & -0.0029 \\
\hline Average difference between series [m] & -0.005 & -0.0049 & -0.0046 & -0.0045 & -0.0044 & -0.0043 \\
\hline RMSE [m] & \pm 0.0098 & \pm 0.0096 & \pm 0.0103 & \pm 0.0102 & \pm 0.0104 & \pm 0.0106 \\
\hline Parameter ex & 0.000029 & 0.000029 & 0.000026 & 0.000025 & 0.000025 & 0.000025 \\
\hline Parameter ey & -0.00005 & -0.00005 & -0.000045 & -0.000048 & -0.000041 & -0.000045 \\
\hline Parameter Ho & -0.00149 & -0.00135 & -0.0015 & -0.00112 & -0.00155 & -0.00105 \\
\hline
\end{tabular}


When analyzing Table 6 , it can be seen that the mean square error of the difference between the two series of measurements increases with the number of fixed points and is about $\pm 1 \mathrm{~cm}$. The average difference between series has a negative value and is about $-5 \mathrm{~mm}$ with an increasing trend. If you take into account the parameters of the " 0 " plane, ex and ey have a decreasing tendency, while $\mathrm{H} 0$ is unevenly distributed. In the even-points, it increases, and in odd ones it decreases. Area no. 1 was characterized by slight changes in the shape of the terrain, but with the large height difference, hence the results are ambiguous.

It can be read from table 7 that the average difference between the series of measurements is in plus and it is within the range of $\pm 1 \mathrm{~cm}$. The mean difference error is $\pm 1.5 \mathrm{~cm}$. Both attributes show a decreasing trend with a growing number of fixed points. The mean error is greater than in the case of area 1 (Table 6), despite smaller land sliding. The ex and ey parameter distributions are differentiated and do not show a clear trend - they rise and drop at different rates. At the same time, the $\mathbf{H O}$ parameter decreases with the increase of fixed points.

The compilation of calculated values for area 3 is shown in Table 8 . Based on this, it can be stated that the mean square difference error is 3 times greater in the case of area 2 (Table 7) and 2 times greater than in area 1 (Table 6). The error is $\pm 5.3 \mathrm{~mm}$. The average difference between the series is ca. $+14 \mathrm{~mm}$. As for the plane parameters, all three tend to increase in value (ex and ey), while the $\mathbf{H O}$ parameter decreases with the increase of fixed points randomly selected for the calculations. The area is different from the first two (Table 6 and 7) because the surface of the terrain that has been measured is concrete, while the first two are grasslands, hence the values are two and three times smaller.

Table 7. Compilation of calculations from the result file for area 2 in the local system.

\begin{tabular}{|r|c|c|c|c|c|c|}
\hline Number of fixed points & $\mathbf{0}$ & $\mathbf{1}$ & $\mathbf{2}$ & $\mathbf{3}$ & $\mathbf{4}$ & $\mathbf{5}$ \\
\hline Min. difference between series [m] & 0.0107 & 0.0097 & 0.0094 & 0.0089 & 0.0088 & 0.0082 \\
\hline Max. difference between series [m] & 0.0107 & 0.0107 & 0.0111 & 0.0109 & 0.0106 & 0.0099 \\
\hline Average difference between series [m] & 0.0107 & 0.0104 & 0.0101 & 0.0099 & 0.0096 & 0.0092 \\
\hline RMSE [m] & \pm 0.0155 & \pm 0.0153 & \pm 0.0151 & \pm 0.0149 & \pm 0.0146 & \pm 0.0144 \\
\hline Parameter ex & -0.000052 & -0.000045 & -0.00005 & -0.00005 & -0.000049 & -0.000046 \\
\hline Parameter ey & -0.000061 & -0.00006 & -0.000061 & -0.00006 & -0.000063 & -0.000066 \\
\hline Parameter Ho & 0.01786 & 0.01684 & 0.01673 & 0.01666 & 0.01646 & 0.01612 \\
\hline
\end{tabular}

Table 8. Compilation of calculations from the result file for area 3 in the local system.

\begin{tabular}{|r|c|c|c|c|c|c|}
\hline Number of fixed points & $\mathbf{0}$ & $\mathbf{1}$ & $\mathbf{2}$ & $\mathbf{3}$ & $\mathbf{4}$ & $\mathbf{5}$ \\
\hline Min. difference between series [m] & 0.0015 & 0.0013 & 0.0011 & 0.0008 & 0.0008 & 0.0009 \\
\hline Max. difference between series [m] & 0.0015 & 0.0015 & 0.0016 & 0.0016 & 0.0016 & 0.0016 \\
\hline Average difference between series [m] & 0.0015 & 0.0015 & 0.0014 & 0.0014 & 0.0013 & 0.0013 \\
\hline RMSE [m] & \pm 0.00540 & \pm 0.00538 & \pm 0.00525 & \pm 0.00533 & \pm 0.00548 & \pm 0.00530 \\
\hline Parameter ex & -0.0001 & -0.0001 & -0.000098 & -0.000097 & -0.000096 & -0.000095 \\
\hline Parameter ey & -0.00003 & -0.00003 & -0.000029 & -0.000028 & -0.000027 & -0.000028 \\
\hline Parameter Ho & 0.00866 & 0.00865 & 0.00843 & 0.00831 & 0.00816 & 0.00811 \\
\hline
\end{tabular}


Table 9. Compilation of calculations from the result file for area 4 in the local system.

\begin{tabular}{|r|c|c|c|c|c|c|}
\hline Number of fixed points & $\mathbf{0}$ & $\mathbf{1}$ & $\mathbf{2}$ & $\mathbf{3}$ & $\mathbf{4}$ & $\mathbf{5}$ \\
\hline Min. difference between series [m] & 0.0029 & 0.0026 & 0.0025 & 0.0024 & 0.0022 & 0.002 \\
\hline Max. difference between series [m] & 0.0029 & 0.0029 & 0.0031 & 0.003 & 0.0031 & 0.0028 \\
\hline Average difference between series [m] & 0.0029 & 0.0028 & 0.0028 & 0.0026 & 0.0026 & 0.0025 \\
\hline RMSE [m] & \pm 0.0057 & \pm 0.0056 & \pm 0.0055 & \pm 0.0054 & \pm 0.0053 & \pm 0.0052 \\
\hline Parameter ex & -0.000033 & -0.000031 & -0.000032 & -0.000032 & -0.00003 & -0.000029 \\
\hline Parameter ey & -0.000054 & -0.000052 & -0.000052 & -0.000051 & -0.000046 & -0.000045 \\
\hline Parameter Ho & 0.009155 & 0.0088 & 0.008737 & 0.008515 & 0.008088 & 0.007774 \\
\hline
\end{tabular}

In Table 9 above, the results of calculations for the mixed area 4 - grass/asphalt are shown (the area with the smallest height difference). The calculations show that the average difference between the series is about \pm 27 $\mathrm{mm}$, while the average error of the difference varies within $\pm 5.5 \mathrm{~mm}$. Both attributes show a decreasing trend with a growing number of fixed points. The ex parameter is ambiguous (it increases and decreases), the ey parameter increases and the $\mathbf{H O}$ parameter decreases in relation to the fixed points. The mean error is a value close to area no. 3, despite twice the average differences between the series of measurements.

Table 10. Compilation of calculations for four areas depending on the area slide.

\begin{tabular}{|r|c|c|c|c|}
\hline & Area 1 & Area 2 & Area 3 & Area 4 \\
\hline $\begin{array}{r}\text { Terrain } \\
\text { differences } \\
{[\mathbf{m}]}\end{array}$ & 4.5 & 2.9 & 1 & 0.5 \\
\hline RMSE [m] & \pm 0.0098 & \pm 0.0155 & \pm 0.0054 & \pm 0.0057 \\
\hline $\begin{array}{r}\text { Parameter } \\
\text { H0 [m] }\end{array}$ & -0.0149 & 0.0179 & 0.0087 & 0.0092 \\
\hline
\end{tabular}

Taking into account the results of the calculations presented in Tables 6-9, it can be concluded (Table 10) that an attribute such as the error of the mean difference between the series of measurements is not accompanied by a decrease with decreasing height (terrain slide). The smallest turned out to be on the compact surfaces (area 3 ) and mixed ones (area 4). The largest error was calculated from data from area 2 (almost 3 times higher than in area 3 and 4). In area no. 1, this error is intermediate between extreme values and is about \pm 1 $\mathrm{cm}$. The actual displacement, calculated on the basis of the analytical difference of the " 0 " function value and the values of the interpolated functions, vary from -14.9 $\mathrm{mm}$ (area 1$)$ to $+17.9 \mathrm{~mm}$ (area 2 ). In area 3 and 4 , they are $+9 \mathrm{~mm}$. The $\mathbf{H O}$ parameter also does not accompany a decrease with the decrease in the value of the height difference. As in the case of RMSE, it turned out to be the smallest at small terrain differences, and the largest on large changes in the terrain elevation. This error points to the high accuracy of mapping the area of the terrain and fitting the DEM into the actual area.

\section{Conclusion}

The original program served to determine real vertical displacements between two measurements. The HO parameter perfectly shows these displacements between consecutive measurements and an artificially assumed theoretical " 0 " plane. It follows that theoretical values of plane parameters can be obtained as a result of calculations, with different combinations of non-fixed points (primary and secondary measurement) and theoretically fixed points. The $\mathbf{H O}$ parameter in areas 2, 3 and 4 displays a decreasing trend with the increase of the number of fixed points, while on area no. 1 (where the largest height difference and discrepancies between measurements were noted), it rises once and decreases once.

The calculated parameters show that the selection of an appropriate measuring technique for the measured terrain, and in principle its surface and height differences, is very important in order to obtain satisfactory results. As shown in this paper, the use of geometric leveling has proved to be sufficient to show that adding fixed points does not increase the accuracy of the obtained model, but it increases the accuracy of the surface parameters obtained. The use of the original calculation program has shown that it is possible to obtain pre-set parameters of the plane and comparing the obtained planes from these two measurements on survey points (not fixed in the field in reality).

In conclusion, the analysis of data in terms of displacements of non-fixed points permanently showed no significant displacements, discrepancies within their determined accuracy or slight changes in the shape of objects, mainly due to direct leveling as not very precise in relation to precise leveling. However, the use of this method seemed justified due to the high speed of data acquisition and processing, the choice of the measured objects, and also the purpose of obtaining this data (terrain surface).

This work was financed by the Polish Statutory Research Grant no. $0401 / 0123 / 17$. 


\section{References}

1. R. Baryła and J. Paziewski, Biuletyn WAT 2/2012, 39-57 (2012)

2. A. Hermanowski, Pomiary przemieszczeń pionowych (Instytut Geodezji i Kartografii, Warszawa, 1993)

3. A. Kwinta, Zeszyty Naukowe Politechniki Śląskiej, Górnictwo, 278 (2007)

4. S. Oszczak, A. Wasilewski, Z. Rzepecka, A. Szostak-Chrzanowska, A. Chrzanowski, Proceedings 11th International Symposium on Deformation Measurements, Santorini, Greece, 2528 May 2003 (2003)

5. A. Nowakowska and A. Rosa, Pomiary przemieszczeń pionowych $i$ poziomych budynku Starostwa Powiatowego w Opatowie (GeoPixel, Wojskowa Akademia Techniczna, Warszawa, 2011)

6. H. Bryś and S. Przewłocki, Geodezyjne metody pomiarów przemieszczeń budowli (Wydawnictwo Naukowe PWN, Warszawa, 1998)

7. K. Czarnecki, Geodezja wspótczesna (Wyd. PWN, Warszawa, 2014)

8. A. Kwinta, A. Szeptalin, T. Gargula, [In:] Archiwum Geomatyki. Pomiary satelitarne w geodezji i budownictwie (Gdańsk, 2010)

9. T. Lazzarini, Geodezyjne pomiary przemieszczeń budowli i ich otoczenia (Państwowe Przedsiębiorstwo Wydawnictw Kartograficznych, Warszawa, 1977)

10. W. Prószyński and M. Kwaśniak, Podstawy geodezyjnego wyznaczania przemieszczeń (Oficyna Wydawnicza Politechniki Warszawskiej, Warszawa, 2006)

11. D. Gościewski, Materiały XX Jesiennej Szkoły Geodezji (Wrocław, 2007)

12. B. Hejmanowska, Archiwum Fotogrametrii, Kartografii i Teledetekcji, Vol. 17 (2007)

13. Cz. Suchocki, M. Damięcka-Suchocka, P. Błoch, M. Stec, Acta Sci. Pol., Geodesia et Descriptio Terrarum 12 (3), 17-26 (2013)

14. J. Wysocki, Przegląd Naukowy Inż. i Kształtowania Środowiska, nr 1 (31), 102-113 (2005)

15. C. Childs, Interpolating surfaces in ArcGIS Spatial Analyst (ESRI Education Services, 2012)

16. J.P. Mund, Geospatial statistics and spatial data interpolation methods (GIS'EM at Eberswalde, 2013)

17. S.M. Robeson, Cartog. Geog. Inf. Sys., 24 (1), 3-20 (1997) 